\title{
Information space of the economic management system in the business management system
}

\author{
Evgenia Muratova $^{1 *}$, Elena Kravchenko ${ }^{2}$, Anna Sukhoveeva ${ }^{2}$, and Olga Andreeva ${ }^{2}$ \\ ${ }^{1}$ Don State Technical University, 344002, Rostov-on-Don, Russia \\ ${ }^{2}$ Rostov State University of Economics, 344002, Rostov-on-Don, Russia
}

\begin{abstract}
The process of possible automation of developing control actions is considered and presented in the article as the mathematical model that shows the economic mechanism of one or more business processes along with the formalized description of management accounting and controlling procedures. As a result, the information space model of the economic management system is obtained which is filled with a set of possible states created.
\end{abstract}

\section{Introduction}

Currently, the issues of efficient economic management are relevant to the majority of business structures in Russia due to the fact that they are constantly improving in order to maintain their development, implement strategies and ensure a high level of competitiveness. In the context of the dominant crisis in the world (taking into account the coronavirus pandemic), including the Russian economy, the businesses are predominantly focused on optimizing their costs along with the adjustment of innovation and investment flows. The World Economic Forum (Davos, 2021), which, as a rule, determines the goals of the world economy for the next year, showed the decrease in investment activity of most countries. As noted by RBC Trends, "The main trends on the forum's agenda are associated with technologies and innovations », among which «The Ethics of Artificial Intelligence» and «Cyber Pandemic and Cybersecurity» are of great interest [1]. The speeches included the indications of positive and negative aspects of the introduction of artificial intelligence designed to help humanity. Therefore, the issues of the efficiency of economic systems' functioning within the context of current trends of economy development, digitalization and introduction of advanced technologiescome to the fore, including when creating the information field of the economic management system [2].

Accordingly, the topic of developing the most adequate and efficiently functioning information space of the economic management system on the basis of the concept of the business management systemic paradigm remains relevant. This concept is explained by the possibility of increasing the profitability of business structures by applying the necessary methods of receiving, transferring, storing, and presenting economic information. The key to the success of a modern organization is largely its ability to develop the information space that ensures the efficiency of analysis, storage, and use of management information.

*Corresponding author: geniahab@mail.ru 


\section{Materials and methods}

The development of economic management system should include the following stages: identification of control actions by creating the information space; development and validation of management indicators and criteria; development of methodology in decisionmaking; designingthe corresponding forms of documents. Consequently, the efficiency of the economic management system functioning depends directly on the proper developmentof the information space.

The information space development for economic management as part of the company management system essentiallyincludes integration of a set of financial, economic, statistical and mathematical methods and models into one business system through the use of production, technical, organizational, methodological, information and software resources. Economic information reflects the results of the functioning of production business processes, their financial and economic component, including the organization of distribution and consumption of material resources and services.

Decomposition of the structure of the company's management information space into subsets of management data (economic, organizational, production information) makes it possible to assess the role and quality of managerial decisions including their impact on the result (for example, the company's balance sheet) and to adjust them in due time. The same principle is used to divide the economic management system into subsystems when modeling the company'seconomic processes and tasks, for which the decisions should be developed or adjusted under certain conditions, criteria and restrictions.

The process of automating the development of control actionscan be basically represented in the form of a mathematical model characterizing the economic mechanism of one or more business processes and describing the management accounting and controlling procedures in a formalized way. The result includes an information space model of the economic management system which is filled by a set of states created. The input parameters in this system can be individual elements of financial and economic activities and their results, while the output parameters, characterizing the state of the system, are the balance sheet and some functions showing the efficiency of operation of local business processes and company as a whole.Management of the system state through modeling and creation of the single information space of the economic management system provides an opportunity to seek and manage the efficient control actions. It should be noted that in practice this model turns out to be a simulation and this approach does not give a clear solution, since the solution is formed as a result of forecasting the system state, but it provides the information basis needed for making an effective decision. One example is the application of the theory of Markov processes considered by the authors in earlier writings $[2,3]$.

The consideration of the process of managing economic systems from the point of view of the development of J. Kornai's theory of systemic paradigm can be found in a lot of contemporary economic studies [3]. For example, the study of economic processes as a result of interaction of economic systems is considered in the work of G.B. Kleiner entitled "System paradigm and system management". Large economic systems usually include organizations. Thus, the systemparadigm studies the economic processes in the organization through the study of its subsystems.Furthermore, economic systems are sometimes understood as economic groupings, socio-economic projects, etc., and in this case their economic operation is seen as a result of their participation in stronger systems, such as the company as a whole oreconomic projects. This approach indicates that economic systems are diverse in their content, line of action, and they include economic processes, projects, objects and environments. 
On the basis of a more detailed study of this issue, the authors of the system-based management concept proposed the following four economic systems: object-based, process-based, environment-based and project-based. The parameters and features of these economic systems are presented in summary Table 1.

Table 1. The specifics of the system-based management concept

\begin{tabular}{|c|c|c|c|}
\hline $\begin{array}{c}\text { System } \\
\text { type }\end{array}$ & $\begin{array}{c}\text { Classification } \\
\text { attributes }\end{array}$ & Examples & Description \\
\hline $\begin{array}{l}\text { object- } \\
\text { based } \\
\text { systems }\end{array}$ & $\begin{array}{l}\text { certainty of territorial } \\
\text { boundaries and } \\
\text { uncertainty of the } \\
\text { duration of operation }\end{array}$ & $\begin{array}{l}\text { economic systems } \\
\text { (e.g. enterprise) }\end{array}$ & $\begin{array}{l}\text { a typical representative of the } \\
\text { class of object-based systems; the } \\
\text { life cycle of the company is } \\
\text { usually not determined, but the } \\
\text { territorial boundaries are clearly } \\
\text { defined }\end{array}$ \\
\hline $\begin{array}{l}\text { process- } \\
\text { based } \\
\text { systems }\end{array}$ & $\begin{array}{l}\text { uncertainty of } \\
\text { territorial boundaries } \\
\text { and certainty of the } \\
\text { duration of operation }\end{array}$ & $\begin{array}{l}\text { business processes } \\
\text { (e.g. innovations) }\end{array}$ & $\begin{array}{l}\text { it has no territorial boundaries a } \\
\text { priori, but fades out upon the } \\
\text { disappearance of the source of } \\
\text { development }\end{array}$ \\
\hline $\begin{array}{l}\text { environme } \\
\text { nt-based } \\
\text { systems }\end{array}$ & $\begin{array}{l}\text { uncertainty of } \\
\text { territorial boundaries } \\
\text { and uncertainty of } \\
\text { duration of operation }\end{array}$ & $\begin{array}{l}\text { economic systems } \\
\text { (e.g. economic } \\
\text { management } \\
\text { system) }\end{array}$ & $\begin{array}{l}\text { the absence or presence of the } \\
\text { time and space borders actually } \\
\text { appears to be the key feature of } \\
\text { economic systems' differentiation }\end{array}$ \\
\hline $\begin{array}{l}\text { project- } \\
\text { based } \\
\text { systems }\end{array}$ & $\begin{array}{l}\text { certainty of territorial } \\
\text { boundaries and } \\
\text { certainty of the } \\
\text { duration of operation }\end{array}$ & $\begin{array}{l}\text { projects, project- } \\
\text { based activities of } \\
\text { the company }\end{array}$ & $\begin{array}{l}\text { limited territory and duration of } \\
\text { implementation }\end{array}$ \\
\hline
\end{tabular}

The point is that space and time are considered as the key or primary resources of the economic system which are used for the production (exchange, consumption or redistribution) process implementation and basically represent the space-time component of the potential of economic systems.

It should also be noted that G.B. Kleiner clarifies «... when we talk about the unlimitedness or non-placement of the system in time. This does not mean that this system has existed from time immemorial and forever. It only means that a priori immanently inherent temporal limitations of its existence are absent, and its life duration is unknown. Such a system behaves and is perceived by a public observer as if its operation will last forever (time unlimitedness for the companies is reflected in the generally recognized principle of «going concern»)» [4].

It is important to emphasize the fact that the formulated restrictions, according to which systems are divided into classes, cannot be considered dogmatically. That is, when it comes to environment-based systems, which usually refer to internal prescriptive regulatory documents and at the same time have their own timelines of their introduction and expiration (or revision), its characteristicsis considered to be conditional. Consequently, other classes of systems can be studied in a similar way. In this context the development of the system-based management concept seems to be quite promising in terms of studying economic processes in the system (organization), and application of this approach to study the characteristics of economic management is also of interest.

The development of the theory of interaction of economic, production and organizational subsystems in the business management system, as well as the issues of 
making effective management decisions, substantiating the overall direction of company's development in the light of the theory of economic systems can be the cornerstone for creating a promising information space for decision-making and successful operation of the economic system. In our opinion, the application of this approachcan help expand the boundaries of understanding economic theory, initiate the launch of new developments to improve economic processes, reflect economic analysis from the different perspective, due to which the results of some subsystems' operation can be applied to achievemore successful operation results of other subsystems. In other words, the study of therelationships of subsystems' parameters, which tend to change over time due to various factors (including the form of ownership, management features, external and internal environment, etc.), makes it possible to create an information field for decision-makingin the subsystem of economic management. Similarly, management information is accumulated in the subsystems of production and organizational management, which contributes to the corresponding adjustment ofmanagement decisions and affects the management object (production, sales, procurements, etc.) in a specific time period. This emphasizes and supplements the idea of distinguishing three types of management and their relationships with each other.

The business management system can be presented in the form of intersecting three types of management, which in turn can be seenas a variety of overall and local areas of responsibility. The areas of mutual contact belong to the overall areas of responsibility, and in the absence of intersection the methods of the type of management, which has the relevant competencies, are mainly used to solve the issues. Control actions built on the company information space should take into account the factors of the external environment, correspond with the guidelines of this organization (marketing, social and ecological components) and, as a result, solve the issues related to restrictions, conditions, opportunities.

So, according to the system-based approach applicationfor company's management, the place of economic management in the structure of a large economic system is determined and shown in Figure 1.

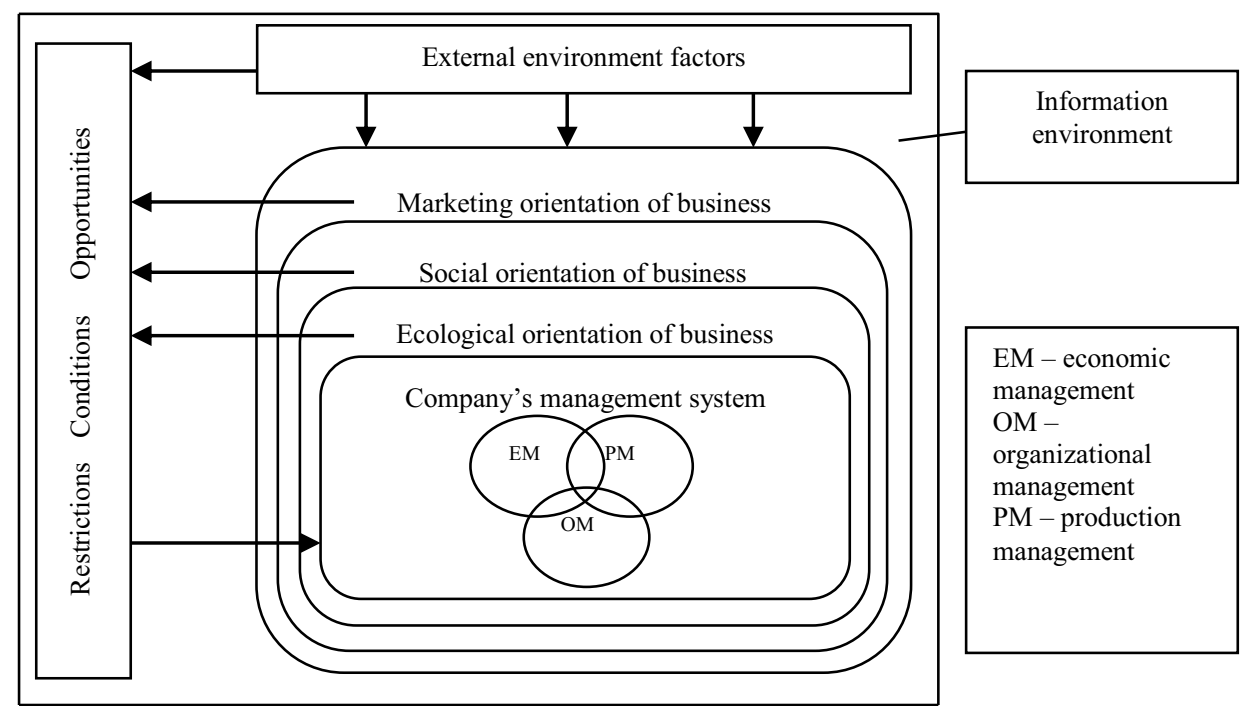

Fig. 1. Scheme on the interaction of company's management types and information space 
The economic cycle characterized by the constancy of cash flows, the processes of production and transformation of resources in the field of economic activity, is viewed through the prism of many states of economic systems that interact with each other, which in turn makes it possible to assume the viability of the systemic paradigm. As a rule, the key participants of the economic circulation are not autonomous individuals, but relatively autonomous (local) economic systems. The intersystem space has a relevant structure and performs the function of the movement of material and non-material goods. The internal system environment has a similar structure, providing the internal and external space of the system. According to the G.B. Kleiner's view of systemic paradigm, «the pattern of the natural operation of the economic system is determined not so much by its scale as by the features of its nature, including the configuration of borders with the environment» $[4,5]$.

\section{Equations and mathematics}

As is shown in Figure 1, the intersecting areas (sets e, o, p) are interdependent, which could be expressed as follows:

$$
\begin{gathered}
\exists e, \text { o, p, ci, cj, ck, cl : }(\mathrm{e} \in \mathrm{E}) \Lambda(\mathrm{e} \notin \mathrm{O}) \Lambda(\mathrm{e} \notin \mathrm{P}) \Lambda(\mathrm{o} \in \mathrm{O}) \Lambda(\mathrm{o} \notin \mathrm{E}) \Lambda(\mathrm{o} \notin \mathrm{P}) \Lambda(\mathrm{p} \in \mathrm{P}) \Lambda(\mathrm{p} \notin \mathrm{O}) \Lambda(\mathrm{p} \notin \mathrm{E}) \\
\Lambda(\mathrm{ci} \in \mathrm{E}) \Lambda(\mathrm{ci} \in \mathrm{O}) \Lambda(\mathrm{ci} \in \mathrm{P}), \Lambda(\mathrm{cj} \in \mathrm{E}) \Lambda(\mathrm{cj} \in \mathrm{O}) \Lambda(\operatorname{cj} \in \mathrm{P}) \Lambda(\mathrm{ck} \in \mathrm{O}) \Lambda(\operatorname{ck} \notin \mathrm{E}) \Lambda(\mathrm{ck} \in \mathrm{P}) \\
\Lambda(\mathrm{cl} \notin \mathrm{O}) \Lambda(\mathrm{cl} \in \mathrm{E}) \Lambda(\operatorname{cl} \in \mathrm{P}),
\end{gathered}
$$

where $E$ is the „Economic management” set;

$e$ includes features inherent only to economic management;

$O$ is the „Organizational management” set;

$o$ includes features inherent only to organizational management;

$P$ is the „Production management" set;

$p$ includes features inherent only to production management;

$c i$ includes common features of economic, organizational and production management;

$c j$ includes common features of economic and organizational management;

$c k$ includes common features of organizational and production management;

$c l$ includes common features of economic and production management.Economic information reflects the processes of production, financial and economic activities of the economic system, the organization of distribution and consumption of material resources and services within the economic management system in the concept of the business management systemic paradigm. Economic information is characterized by a significant volume, duplication, changes and transformations, mathematical calculations. It has a certain structure, where the minimal element is an economic indicator.

Roadmaps can be used to develop the company's information space. The object of roadmap is an economic system with itsdevelopment strategy, goals and plan; mapping makes it possible to integrate them, building the main stages of their achievement within the timeline according to the principle „from the past through the present to the future". The use of roadmaps helps to consider probable scenarios and their efficiency, see the potential effectiveness of management decisions taken and promptly adjust them. In the process, forecasting the options for the future state of the economic management system is based on the collection of expert economic information about the business process, technology, product, service, etc.

Thus, the result of roadmap development is a set of alternative scenarios for the system development with the possibility of correcting and eliminating potential bottlenecks. Furthermore, current management theory does not classify roadmaps as a strategic management tool, considering it only as a good graphical representation of system 
development options whichsimplifies the interpretation of the situation for control actionworking-out.

In general, the tasks of roadmap creationinclude the information support of the process of defining control actions for the management subject (company, business process, etc.) development, butlocal road maps are usedwhen a problem solution or innovative development of a control object is required. Therefore, roadmaps based on the mechanism of economic management areneededto create the information space of the economic management system.

\section{Results}

The economic management mechanism in the company's management system includes the following stages: modeling and analysis of business processes, management accounting and controlling, integrated economic analysis, corrective actions, which, in fact, represent the road map. The purpose of creating a roadmap of the information space is to increase the number of effective management decisions based on the qualitative building of the information field of economic management within the company's management system, which is shown in Table 2 .

Table2. Economic management roadmap in the business management system

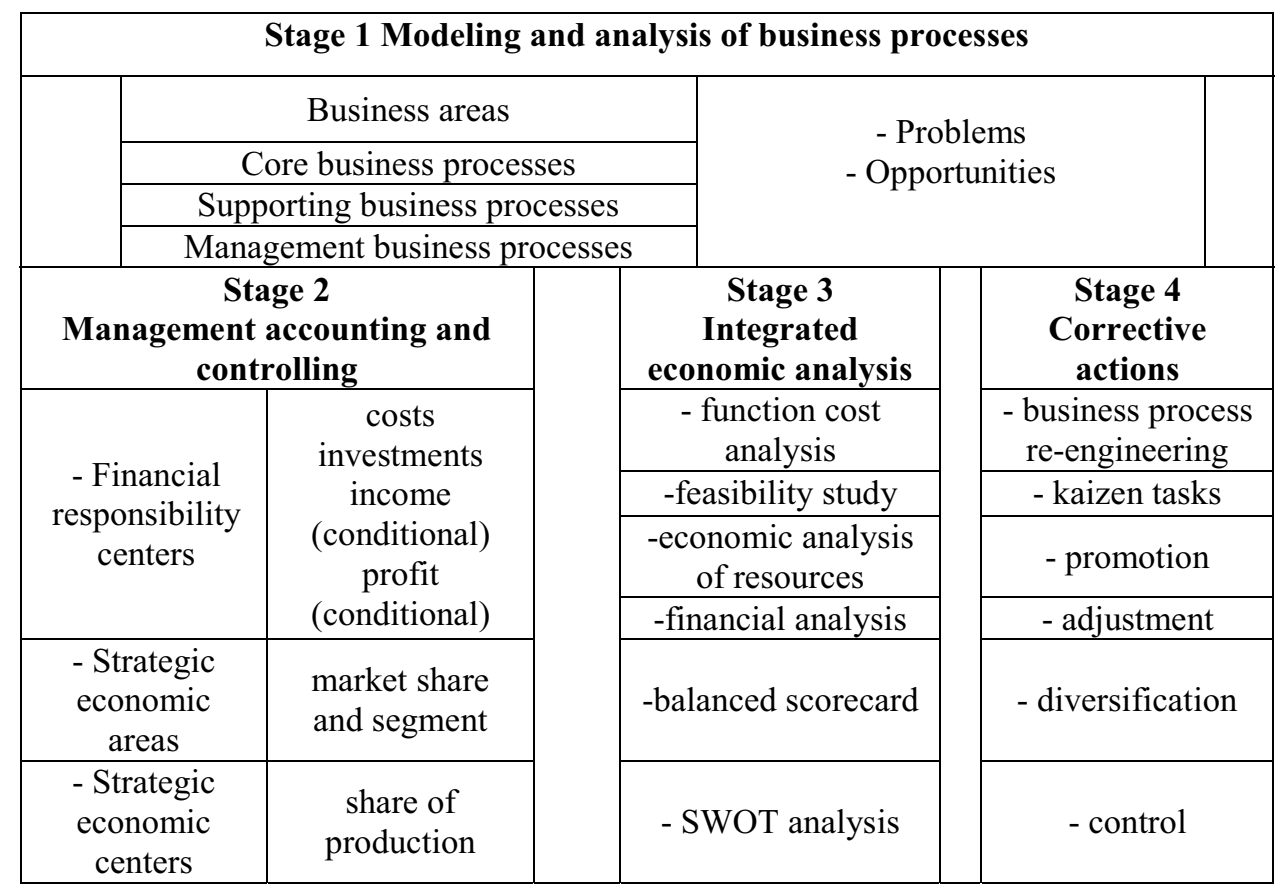

In our opinion, roadmapshelp not only to create scenarios for the management subject development and information space formation of economic management in the company's management system for making effective management decisions, but to identify the areas for improvement and development potential of the management subject.

Identification of threats and growth opportunities at the first stage ("Modeling and analysis of business processes") makes it possible to create a business process model in which the business strategy, external environmental factors (selected market data, technological innovations, etc.) and the available resource potential are integrated. The 
process of roadmap creation involves the establishment of a working group, the members of which have a clear understanding of the structure of a specific business process, its strengths and weaknesses along with its development plan working-out.

At the second stage ("Management accounting and controlling") it is important to understand what resources (capacities, technologies, etc.) the company has at a certain moment of time, since roadmaps have a spatial-temporal characteristic. Identification of bottlenecks is also implemented at this stage. Roadmaps help to build the information space of the economic management system, on the basis of which the gaps in the company's strategy can be found and addressed in the future.

The third stage ("Integrated economic analysis") makes it possible to identify the results of the operation of business processes, analyze them andmake the necessary adjustments in accordance with the types of activities. Combining multiple business process roadmaps help to strategically use technologies for the company's product line. The significance of the possible synergy occurrenceshould also be noted,which at this stage provides an explanation for some economic achievements of the system as a whole (for example, decrease inoverhead costs) [3].

The fourth stage «Corrective actions», helps to set more realistic goals in order to use company's time and resources in the most efficient way. However, it should be noted that some solutions, including innovative developments, can lead to theeconomic systemimbalance, since at this moment the entire system is adjusting and the cost of resources is increasing. Moreover, on the one hand, the changesmay not be significant for the system or its specific elements, but, on the other hand, the changes can dramatically modify the economic mechanism of the entire system.

When creating a roadmap, as a rule, great interest and attention is paid to such aspects as: business area, business process, technology, consumer needs, investments, etc. Therefore, roadmap development basically shows the effects of information exchange among stakeholders and participants which are interested in the control object development. So, for example, focusing on the roadmap a dialogue can be established between counterparties and company's management concerning the overall vector of development of economic relations. Furthermore, it should be noted that when working with large-scale projects it is necessary to use the methods for standardizing the presentation and analytical processing of data along with a formalized approach to demonstrating the required types of activities and the set of functions of its participants to ensure efficient information exchange.

As a rule, information systems are most often used to describe information or economic and mathematical models, which are divided into two types according to their specifics: abstract and event-driven. Abstract models present systemic vision of the modelled object, and event-driven models record events in the system and help to simulate the system state in order to predict its behavior.

Transformation of economic and mathematical models to the applied field implies an extensive transfer of data based on information models and integration of methods for collected data processing for their correct perception and development of effective management decision. Thus, Figure 2 shows a model that reflects management as an action transferred to the information model, as well as the process of data processing in different architecture layers.

The activities described using the management structure in the form of economic, organizational, production subsystems and the management subject (core business process) demonstrate the building logic (activitylogic). Business process decomposition to elementary work and activity logic identification in the information system is transformed into a set of roles. The information layer is represented by information objects, their functions and actions, reflecting the transformation of basic objects. 


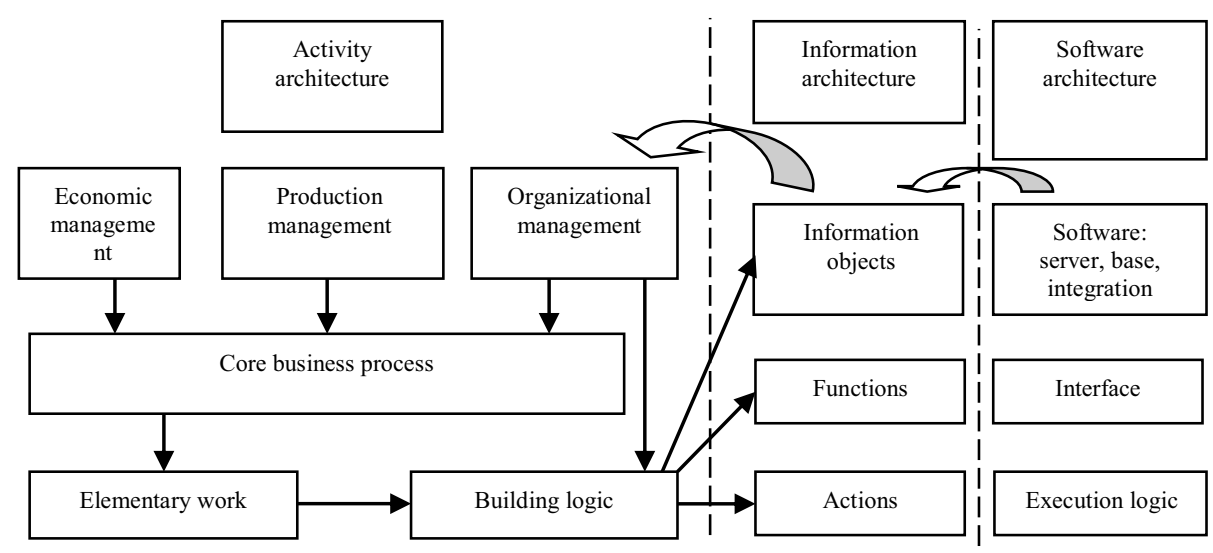

Fig. 2. Information model of activity and data processing procedures in architecture layers

The software layer includes software for the purpose of describing tools of information base creation and methods of analytical data processing; execution logic; a set of interfaces for information communication with users (for possible data entry and editing).

\section{Conclusions}

Thus, the study defined the place of economic, organizational and production management in the organization's management system along with their interaction.

The process of possible automation of developing control actions is considered. It is presented in the form of a mathematical model that shows the economic mechanism of one or more business processesalong with the formalized description of management accounting and controlling procedures. As a result, the information space model of the economic management system is obtained which is filled with a set of possible states created.The key aspects of the effective information space development of the economic management in the concept of the systemic paradigm of the company's management are considered. The roadmap developed helps to create an information space for economic management system that ensures the efficiency of analysis, storage and use of management information.

\section{References}

1. N.S. Plaskova, N.A. Prodanova, A.S. Samusenko, E.A. Erzinkyan, K.A. Barmuta, R.A. Shichiyakh, International Journal of Engineering and Advanced Technology 9 (1), 2913-2916 (2019). DOI: 10.35940/ijeat.A1213.109119.

2. E. Muratova, D. Muratov, E. Kravchenko, A. Sukhoveeva, O. Andreeva, E3S Web Conf. 210, 05010 (2020). doi.org/10.1051/e3sconf/202021005010

3. E. Muratova, D. Muratov, E. Makarenko, S. Shepelev, O. Korobeynikova, V. Chegge and Y. Kabanova, E3S Web Conf. 175, 01009 (2020). doi.org/10.1051/e3sconf/202017501009.

4. G. Kleiner, Economic revival of Russia (2020). DOI: 10.37930/1990-9780-2020-2-6459-69.

5. G. Kleiner, Ecosystem development in the Russian financial sector (2020) DOI: 10.29141/2218-5003-2020-11-4-1.

6. A. Solonenko, L. Medvedeva and Y. Mostovaya, E3SWeb Conf. 175, 13010 (2020). doi.org/10.1051/e3sconf/202017513010. 
7. V.V. Mazur, K.A. Barmuta, S.S. Demin, E.A. Tikhomirov, M.A. Bykovskiy, International Journal of Economics and Financial 6 (1S), 270-274 (2016).

8. L.V. Borodacheva, A.F. Goloborodov, A.I. Guseva, A.A. Drozdova, M.P. Glyzina, International Journal of Economics and Financial 6 (1S), 306-311 (2016).

9. Y. Tsarev, E. Adamcikova, M. Najie, MATEC Web of Conferences 224, 05019 (2018). DOI:10.1051/matecconf/201822405019/

10. R. Aleshko, L. Petrova, E. Ivanova, A. Plotnikova, M. Melnikov, V. Antonov, International Journal of Engineering and Advanced Technology 9(1), 7517-7523 (2019). doi:10.35940/ijeat.A2201.109119

11. T. V. Morozova, T. Polyanskaya, V. E. Zasenko [et al.], International Journal of Applied Business and Economic Research 15 (23), 117-124. (2017)

12. I. Khozyaev, V. Ladyanov, L. Enalyeva, M. Balinskaya, V. Zharov, E3S Web Conf., 135, 01103 (2019). doi.org/10.1051/e3sconf/201913501103.

13. S.S. Demin, E.N. Dombrovskaya, V.A. Mushrub [et al.], Espacio 39 (31), 2018.

14. I.S. Kobersy, K.A. Barmuta, S.S. Muradova, L.I. Dubrova, D. Shkurkin, Mediterranean Journal of Social Sciences 6(3 S2), 25-30 (2015). DOI 10.5901/mjss.2015.v6n3s4p25.

15. K. Timoleanov, D. Savenkov, L. Gorgadze, MATEC Web of Conferences 224, 05020 (2018). DOI:10.1051/matecconf/201822405020.

16. Xin Su, Keshu Yu, Miao Yu, Chaos, Solitons \& Fractals 24 July (2019) doi.org/10.1016/j.chaos.2019.06.020 